\title{
Estética del Arte Rupestre: Trazo en la Roca, Marca del Espíritu, Ventana al paisaje
}

\section{Rock Art Aesthetics: Trace on Rock, Mark of Spirit, Window on Landscape}

\author{
ThOMAS HeYD* \\ La belleza y calidad artística de estos dibujos probablemente \\ no fueron intencionales [...] \\ Independientemente del uso prehistórico de estos paneles, \\ muchos paneles son obras de arte [...]
}

(Keyser, 1992:125)

\section{RESUMEN ABSTRACT}

Este trabajo pretende analizar la relación entre estética y arte rupestre. Comienza abordando la cuestión de si el arte rupestre debería considerarse arte, sigue con la aclaración de aspectos específicos de esta forma de estética, y finaliza con una evaluación del significado que pueda tener para el presente. Sobre el camino examina posibles objeciones que se puedan presentar desde puntos de vista éticos y epistemológicos. Llega a la conclusión que las representaciones en las rocas pueden ser una rica fuente de
This paper illuminates the relationship between aesthetics and rock art. It begins by addressing the question whether rock art may be considered art, continues with an elucidation of specific aspects of this kind of aesthetics, and closes with an assessment of its significance for the present. On the way it examines potential objections both from an ethical and an epistemological point of view. It concludes that marks on rock can be a very rich source of aesthetic experience, and that the aesthetic approach to rock art

* Departamento de Filosofía, University of Victoria, Victoria, Columbia Británica, V8W 3P4, Canadá, heydt@uvic.ca 
experiencia estética, y que la perspectiva estética nos facilita la apreciación de estas representaciones, de las personas que las hicieron y que vivieron (o viven) con ellas, $y$ del territorio en que están ubicadas.

\section{PALABRAS CLAVE}

Arte rupestre, estética, arte, significado, pictografías, petroglifos. facilitates our appreciation of the markings themselves, the people who made and lived (or live) with those marks, and the land in which these marks subsist.

\section{KEY WORDS}

Rock art, aesthetics, art, significance, pictographs, petroglyphs.

Después de viajar trescientos kilómetros hacia el noroeste de Cairns (parte norte del estado de Queensland, Australia) por carreteras generalmente sin asfaltar se llega a un poblado llamado Laura. Laura se halla en una región del interior que gran parte del año es seca, aunque tiene valles con mucha vegetación que sirven de hogar a aves tropicales, tales como los coloridos kukaburras y los cocatús negros. En las tardes se congregan innumerables «zorras voladoras» (murciélagos fruteros, genus Pteropus) en estos lugares, y se pueden hallar varias clases de boniato (genus Dioscorea) y árboles frutales, esto sí, si se sabe dónde buscarlos. Antes de la llegada de los Blancos esta especie de huerto natural servía a los Aborígenes de espacio habitable, y hoy en día aún se pueden admirar sus manifestaciones culturales, pues hay pinturas y grabados altamente expresivos que están al refugio del sol y de la lluvia, escondidos en abrigos bajo los acantilados, y en estrechos espacios debajo de grandes peñascos.

La región de Laura tiene como característica especial las imágenes de espíritus supuestamente malévolos llamados «quinkans», pero pueden distinguirse muchas otras representaciones en los incontables paneles rupestres realizadas por los habitantes nativos de la zona'. Siguieron con sus pinturas hasta que fueron forzados a dejar sus formas de vida ancestrales por los administradores europeos. Cada panel de arte rupestre tiene su propio carácter: en algunos predominan imágenes de mujeres con alarde de poder e importancia, en otros hay representaciones de serpientes venenosas, y en otros parece que están retratados policías blancos y negros pintados cabeza abajo. Un panel representa curiosas imágenes de un ser humano que se transforma en batata, o al revés, de un hombre que toma la apariencia de tubérculo.

El arte rupestre de la región de Laura ha sido objeto de considerables proyectos de investigación arqueológica e incluso se han excavado ciertos sitios (Cole,

1 En este texto uso el término «representación» para indicar las marcas pintadas o grabadas, realizadas o presentadas intencionalmente por los seres humanos, que generalmente se consideran como parte del corpus de arte rupestre. A pesar de usar este término no pretendo cerrar el debate sobre si cualquiera de las marcas determinadas de esta manera necesariamente representan algo. Al contrario, quiero dejar abierta la posibilidad de que a menudo las marcas en cuestión sean expresivas pero no representativas en el sentido estricto de presentar otra vez, o sea, de imitar o simbolizar algo por medio de una imagen o marca. 


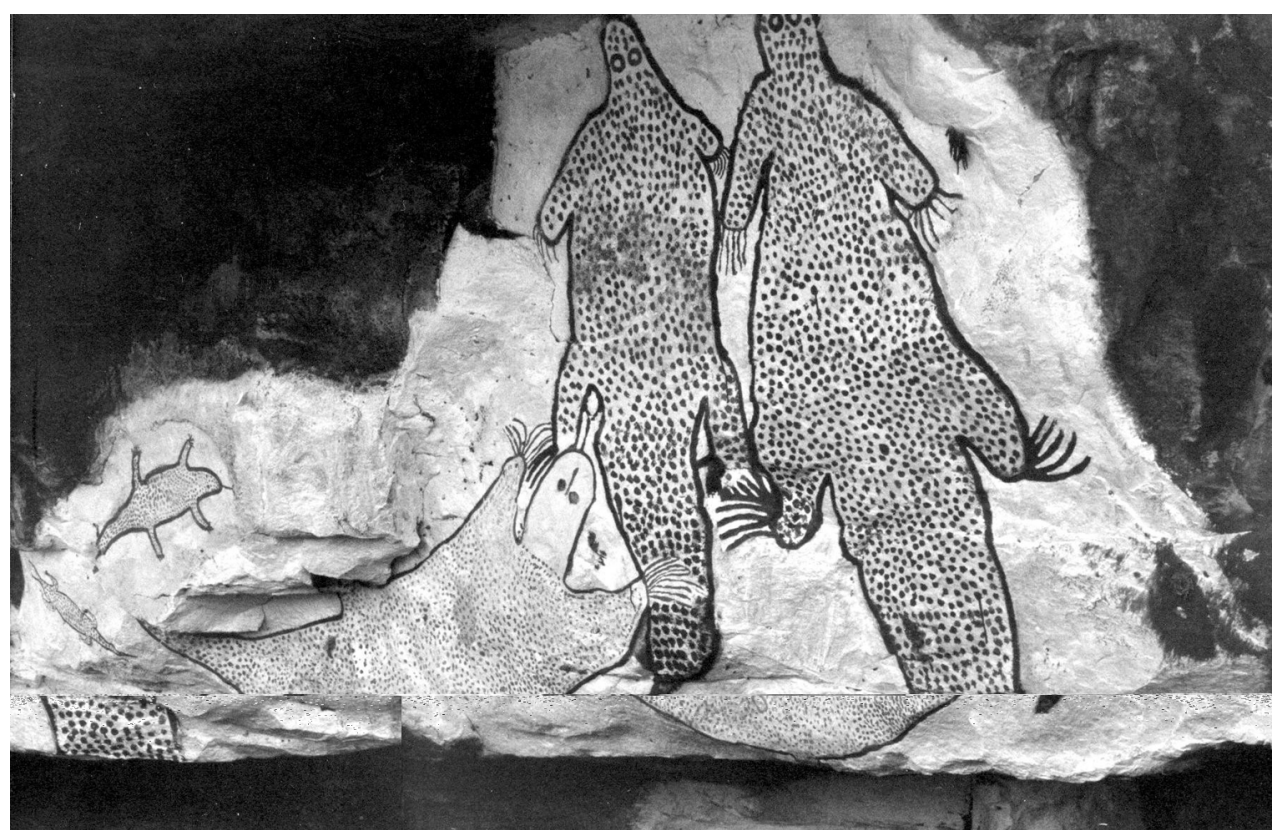

Fig. 1. Zoomorfos: pintura en un abrigo mostrando figuras con tendencia antropomórfica, Australia central (Thomas Heyd, 2000).

1995). El objetivo de tales excavaciones ha sido «extraer información sobre los sistemas culturales prehistóricos» (Morwood, 1992:160). Más específicamente, se quieren comprender los métodos y las técnicas empleadas en la realización del arte rupestre, los «patrones cronológicos, geográficos y estructurales» exhibidos, y «las relaciones funcionales [del arte rupestre] con la ideología, la organización social, la economía, etc.» (Morwood, 1992:60). Estos propósitos concuerdan claramente con lo que se puede esperar de ciencias sociales como la arqueología y la antropología. Lo que queda casi totalmente fuera de estos estudios, sin embargo, es el valor estético de estas representaciones en superficies rupestres².

Mi propia experiencia me convence de que el arte rupestre puede ser tan estéticamente estimulante como las obras artísticas que tienen sus raíces en las prácticas, concepciones y convenciones del arte que tiene su origen en la Europa moderna ${ }^{3}$, y que ahora se puede encontrar en casi todas partes del mundo. Ésta

2 La Estética interviene principalmente como auxiliar, en la determinación de «estilos». Esta información se utiliza para la comprensión de la difusión de culturas y la interacción entre varios grupos dentro de áreas geográficas concretas. Cf., por ejemplo, Cole y Trezise (1992), pero véase también, entre otros, Barry (1991), donde se plasma un estudio amplio y convincente de la estética del arte rupestre de Writing-On-Stone (Alberta, Canadá), e ilustra cómo las imágenes fueron concebidas para proporcionarles «significados serios» o importantes a sus creadores.

3 Utilizo el término «Europa moderna» para referirme a lo que en ciertos contextos se designa con el término «Occidente»; uso el término «Europa moderna» porque hace referencia específica a un período particular y a una región de influencia. En contraste, el término «occidental», y su orientación espacial hacia el oeste, no tienen esos referentes tan explícitos, aunque históricamente se identifican. 
me parece una razón suficiente para conceder más atención a la estética del arte rupestre ${ }^{4}$. En este artículo, comenzaré por un análisis de su recepción como arte. Después me propongo la discusión de algunos aspectos de importancia en la apreciación del arte rupestre. Por último, propongo que el arte rupestre nos proporciona una perspectiva profundamente elocuente sobre la continuidad de la producción de arte entre los seres humanos, sobre los pueblos que nos precedieron y crearon el arte rupestre, y sobre las tierras en que están ubicadas estas manifestaciones de arte que abarca tan largos períodos de la existencia humana sobre este planeta.

\section{ARTE Y ARTE RUPESTRE}

Hay arte rupestre en todas partes del mundo menos en la Antártica. Principalmente se encuentra en abrigos debajo de acantilados y dentro de cuevas, pero también en las paredes de grandes rocas independientes ${ }^{5}$ e incluso en superficies rupestres planas a nivel del suelo. El arte rupestre es muy diverso, variando desde simples raspados superficiales hasta complejas composiciones pictóricas en las que se combinan figuras antropomórficas, zoomórficas y de otros tipos, conformando paneles a menudo muy vistosos. Habitualmente los dibujos y las pinturas que se localizan sobre superficies de roca se denominan "pictografías», mientras que las superficies rocosas que han recibido piqueteados, raspaduras o abrasiones generalmente se denominan «petroglifos».

La edad de los paneles de arte rupestre varía mucho. Algunos se han datado hace 32000 años (como es el caso de la Grotte Chauvet, en Francia), mientras que de otros se sabe que fueron realizados bastante recientemente, incluso en los años

\footnotetext{
4 Mi propuesta de considerar el arte rupestre desde el punto de vista de la estética toca periféricamente el debate en antropología sobre la existencia del «arte por el arte» en el Arte Paleolítico. Este debate trata la cuestión de si «los [seres humanos] paleolíticos fueron artistas simplemente porque apreciaban las cosas bellas, y que por lo tanto sus trabajos artísticos no tenían un objetivo funcional especial» (Ucko y Rosenfeld, 1971:252). Entre los antropólogos este punto de vista fue rechazado «muy al principio», aunque Ucko y Rosenfeld argumentan que el placer estético podría haber sido la motivación para algunos tipos de arte parietal (1971:281; cf. también Halverson (1987), el cual protagoniza un «renacimiento» de las tesis del «arte por el arte»). A mí me parece que incluso si el Arte Paleolítico tuvo otras funciones aparte de la función estética, esto no significa que sea irrelevante que «las esculturas y pinturas son bellas según nuestros estándares», como afirma Gombrich (1984:23). Como veremos más adelante, independientemente de las motivaciones que hayan sido preponderantes en la producción de una obra de arte rupestre particular, el valor estético del arte rupestre es relevante.

5 Existen muchos ejemplos de arte rupestre sobre grandes cantos en la Costa Oeste de Canadá. Algunos de estos cantos rodados tienen un tamaño considerable, tal que sólo podrían ser movidos por grúas, y otros que pueden ser movidos por cualquier persona (como el canto con grabado de cara que se halla en la colección del Nanaimo Museum, en Vancouver Island). Véase también George Nash, «The aesthetic value of textual images: Pallava script and petroglyphic images on semi-portable stones from Bandung Museum, Indonesia (Western Java)», en Aesthetics and Rock Art, ed. por Thomas Heyd y John Clegg (Ashgate, 2005). Véase también la referencia a los «geoglifos», que son arreglos realizados con piedras portátiles.
} 
1920 o 1930 (Mulvaney, 1996)6. Aunque hay excepciones (como es el caso de los geoglifos ubicados junto a la carretera principal que sigue la costa de la isla de Hawaii) ${ }^{7}$ por lo general se reserva el término «arte rupestre" para las pictografías y los petroglifos producidos fuera de la influencia directa de las sociedades modernas y de origen europeo. El hecho de que el arte rupestre no es una manifestación que proviene de dentro de la cultura prevalente, «occidental», puede generar el interrogante de si es correcto y legítimo considerar «arte» estas manifestaciones.

Respecto a los objetos creados por los seres humanos de sociedades que nos anteceden histórica- (y prehistórica-) mente, en un período inicial de la antropología se asumía que habría que clasificarlos estrictamente según su uso en la sociedad original. Esta práctica se mantenía incluso si las manifestaciones culturales en cuestión tenían gran parecido a objetos que en las sociedades modernas y de cultura europea son considerados como arte. Aunque el autor finalmente no encuentra legítima la argumentación, parece que se podría intentar justificar esta práctica aludiendo al hecho de que la producción del arte, como otras actividades simbólicas, es altamente dependiente de determinaciones conceptuales. Por ejemplo, la pintura a goteo (dripping) sobre lienzos realizada por el pintor estadounidense Jackson Pollock es un aspecto de importancia fundamental en la manera de crear obras de arte de este artista, mientras que lo mismo ejecutado por Leonardo da Vinci seguramente no tendría un significado, ya que ni Leonardo ni sus contemporáneos habrían reconocido tal acción como parte de lo que puede ser la producción artística - a pesar de que nosotros, ciudadanos del siglo XXI, sí pudiéramos hallar algún valor estético en esta técnica llevada a cabo intencionalmente por Leonardo-.

Basándonos en este tipo de raciocinio se podría argumentar tal vez, a fortiori, que el arte rupestre no debe clasificarse como «arte» porque las formas de producir y de pensar las cosas características de la producción artística en nuestra tradición occidental son altamente específicas de esa tradición. Éste es un hecho que a menudo se nos escapa, porque estando inmersos en la cultura occidental, no la reconocemos como "otra cultura» más. En cuanto al quehacer artístico, podemos imaginar que se argumente que, hasta el momento de la globalización de culturas europeas-occidentales, sólo nosotros, representantes de la cultura europea moderna, podemos producir arte porque sólo nosotros tenemos los conceptos necesarios para producir (lo que nosotros consideramos como) arte ${ }^{8}$. Para ilustrar, se

6 Aunque pueda haber importantes diferencias entre el Arte Paleolítico y las representaciones de arte rupestres más recientes (como argumentan Ucko y Rosenfeld, por ejemplo), y además puede haber grandes diferencias entre el arte rupestre de diversas zonas, aquí no comento estas distinciones porque mi interés se centra en aspectos generales de su estética, que pueden ser de relevancia más allá de unas épocas y lugares concretos.

7 Cf. Meighan(1996). El término «geoglifo» hace referencia a alineaciones de piedras sobre superficies rocosas.

8 Éste, por ejemplo, parece ser el resultado de «la caracterización histórico-intencional de la producción de arte» propuesta por Jerrold Levinson. Éste argumenta que si «otra cultura tiene arte, tiene que ser arte, aproximadamente, en nuestro sentido» (Levinson, 1996:154). Aunque Levinson está dispuesto 
puede comparar la situación con las actividades sacramentales: aunque cualquiera pueda pronunciar las palabras correspondientes al voto matrimonial, el decir estas palabras sólo se considera como un convenio legítimo y comprometedor si los participantes en el acto tienen la suficiente comprensión del significado de las palabras pronunciadas. Por lo tanto, según el punto de vista aquí descrito (que, sin embargo, no es la perspectiva del autor), si nos imaginamos que un cierto panel de arte rupestre presenta exactamente la misma información visual que una cierta obra de un artista del contexto moderno europeo u occidental, sólo se debería contar como «arte» el producto del artista moderno (este punto de vista está representado por Dickie (1977-89) y Danto (1977-89)) $)^{9}$.

En las últimas décadas la forma de acceder a creaciones humanas ajenas al contexto del arte contemporáneo ha cambiado notablemente. De pronto el arte tradicional de sociedades de pequeña escala ${ }^{10}$, relativamente libre de las influencias emanadas de las sociedades de tradición europea, que antes solía estar emplazado en las salas de etnología de los museos de Historia Natural, ahora frecuentemente se exhibe junto a los especimenes de las Bellas Artes europeas-occidentales, o en museos de Bellas Artes dedicados a una etnia o región específica ${ }^{11}$. Este cambio de actitud respecto a estos objetos ha recibido apoyo teórico. El filósofo Gene H. Blocker (1994) argumenta que «las poblaciones que producen y utilizan estos objetos manifiestan bastantes de las actitudes y disposiciones artísticas y estéticas como para justificar nuestra denominación de tales objetos como «obras de arte» y de tratarlos como tales».

Blocker argumenta que el uso de la denominación «arte» para un objeto debe ser controlada por criterios más amplios que los que dependen de una afiliación explícita al contexto de arte producido por las culturas modernas enraizadas en Europa. Por lo tanto, según Blocker, aún si alguna sociedad tradicional no tiene el concepto europeo moderno del arte, porque se halla fuera de ese contexto artísti$\mathrm{co}$, si los miembros de esa sociedad despliegan actitudes relevantemente similares

\footnotetext{
a aceptar que podemos hablar de arte «en contextos culturalmente remotos (incluyendo los temporalmente remotos, como, por ejemplo, los prehistóricos), en su opinión esto se justifica sólo porque aquellas manifestaciones culturales son, o progenitoras de nuestras formas artísticas, o porque están apuntando «a los mismos tipos de recepción o de experiencia que son la norma respecto al arte posterior» (Levinson, 1996:168-69). Según este autor el apelativo «arte» se usa con justificación si las manifestaciones en cuestión, o son «proto-arte», o se puede suponer que se produjeron para ser consumidas de una forma parecida a la que son consumidas las manifestaciones que constituyen el estándar de arte para nosotros.

${ }^{9}$ La Teoría Institucional del Arte (Dickie, 1977-89) también apoya este tipo de juicios, dado que, de acuerdo con esta teoría, la existencia de arte requiere la existencia de instituciones apropiadas, que incluye a la categoría de «los artistas», al público que aprecie el arte, a museos, a críticos, etc. Muy probablemente, uno u otro (si no todos) de los requisitos estaría ausente en el caso del arte rupestre, dado que las instituciones requeridas son aquellas comunes al mundo del arte moderno europeo.

10 Para referirme a los objetos artísticos de las sociedades de pequeña escala prefiero usar la expresión «arte tradicional» en vez de otros términos comúnmente usados, como «arte primitivo» (cf. Blocker, 1994) y «arte tribal» (cf. Dutton, 1993:13-22), porque probablemente es el menos cargado de significado prejuicioso y el más simplemente descriptivo.

11 Cf., por ejemplo, Heartney (1994:58-65), quien analiza una exposición itinerante organizada por el Museo de Arte Africano (USA).
} 
a las que desplegarían si tuvieran nuestro concepto de arte de una forma explícita, entonces tenemos razón para afirmar que en esa sociedad tienen arte. La propuesta de Blocker tiene una virtud que se asemeja a otra que se busca en el campo de la traducción entre lenguas: su propuesta nos facilitaría la comprensión de algo que anteriormente nos era opaco. O sea, mientras que nos debe parecer curioso que tengamos la tentación de llamar «arte» a objetos de sociedades que no tienen nuestra tradición de arte, su propuesta nos ayuda a comprender esta tentación como justificable. Siguiendo la analogía con el campo de la traducción, su propuesta, sin embargo, también se topa con el peligro que es característico de toda traducción en cuanto que las traducciones pasan por alto algunos de los rasgos específicos del original que traducen. De esta forma la traducción desnaturaliza y se apropia del original por el acto de su equiparación a algo de nuestro propio contexto. Esto puede tener como consecuencia práctica que nos sintamos autorizados a considerar objetos de estas otras culturas como formas propias de nuestro propio contexto cultural. Larry Shiner (1994) es un estudioso que se ha preocupado por este tipo de consecuencia.

Shiner argumenta que si el concepto «arte» es una construcción que está enteramente arraigada en el contexto europeo moderno-occidental entonces la aplicación de este término a objetos de otras sociedades muy distintas de las nuestras lleva a una forma de apropiación cultural, ya que conlleva una alienación de objetos que originalmente fueron producidos con propósitos distintos y para otros contextos culturales (véase Heyd, 2007b). La exposición en contextos de Bellas Artes de esculturas africanas que originalmente fueron diseñadas para usos rituales es un ejemplo. Shiner argumenta que llamar «arte» a tales objetos simplemente es parte de la estrategia que utilizan nuestras instituciones artísticas para mantener el control sobre las diferenciaciones entre los términos «lo auténtico», «falsificaciones» y «arte para el turismo» (objetos producidos para ser vendidos como souvenirs).

La cuestión de si la traducción y su correlativo, la interpretación, necesariamente implican apropiación, ya se ha debatido durante bastante tiempo, y está bien estudiada en antropología (Clifford, 1988). Sin intentar hacer justicia aquí a este tema tan complejo, quiero proponer, sin embargo, que en su mayoría, los aspectos problemáticos de la traducción y de la interpretación se pueden evitar si se incrementa el grado de especificidad con el que se correlacionan productos de traducción y originales. La idea básica consiste en intentar recuperar al máximo posible la experiencia en que está basado el original en sus culturas de procedencia (Walton,

12 Walton argumenta que «(algunos) hechos sobre los orígenes de las obras de arte tienen un papel esencial en la crítica, dado que el juicio estético descansa sobre ellos de un modo absolutamente fundamental» (Walton, 1970:337). Conocer el contexto originario de las manifestaciones que consideramos como candidatas a ser reconocidas como «obras de arte» puede ser problemático en un sentido especial cuando nos aproximamos a los «comienzos del arte»; se supone que tiene que haber objetos no artísticos que difieren sólo ligeramente de la primera obra de arte, y nos podríamos preguntar como se debería definir esta diferencia (cf. Levinson (1996) y Davis (1993), para una discusión del tema). Creo que 


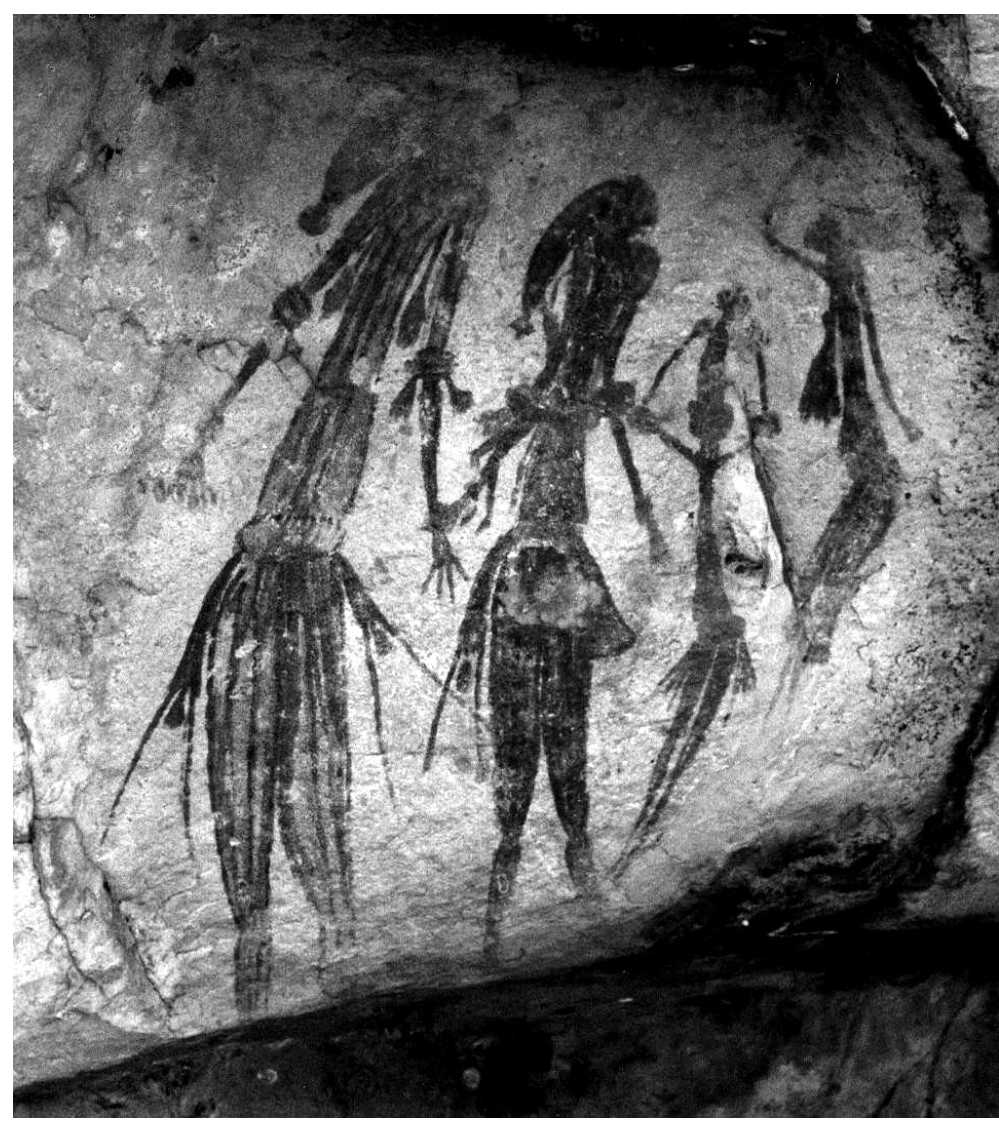

Fig. 2. Bradshaws: pintura parietal en una roca independiente con danzantes tipo Bradshaws/Gion gion, Kimberleys, Australia septentrional (Thomas Heyd, 2000).

1970) $)^{12}$. Aplicando estas consideraciones al arte, propongo que se hable de «arte» respecto a algún objeto si se hallan ciertos aspectos fundamentales (como lo son las actitudes artísticas y estéticas en la producción), constituyentes del concepto de arte en Occidente. No obstante, como tal, esta forma de proceder sólo nos puede facilitar una comprensión muy imprecisa del significado que el original tuvo en sociedades culturalmente muy alejadas de las nuestras.

\footnotetext{
la salida adecuada para este problema ha sido apuntada por Davis cuando afirma que asignamos el estatus de «arte» a las manifestaciones paleolíticas, como las pinturas de Lascaux, "retro-cronológicamente» a través de una clase de "activación retardada» (Davis, 1993:329-346). Esto parece sugerir que nuestro procedimiento es aplicar el término "arte» provisionalmente a ciertos objetos candidatos, $y$, una vez que conocemos la especificidad del contexto de cada objeto, decidimos si debemos revocar esta designación, o alternativamente, extender el concepto «arte» para mantener el objeto en cuestión dentro de esa categoría. Puede observarse que esta descripción, de cómo procedemos respecto al concepto de "arte», está enraizada en la idea de Wittgenstein de parecidos de familia, o en la noción de Quine de interdependencia de creencias.
} 
Si aplicamos este análisis al arte rupestre esto implica que muchas de estas manifestaciones deben ser consideradas como arte ya que gran parte de la producción de arte rupestre probablemente estuvo acompañada por las actitudes relevantes. Podemos asumir que esas actitudes estéticas y artísticas estuvieron presentes observando las demandas estructurales inherentes en la creación de cualquier pintura y grabado. No obstante, si queremos llegar a apreciar el arte rupestre por sus propios valores estéticos tenemos que ir más allá de la suposición general de que en su producción intervinieron juicios estéticos y artísticos. Para detectar los significados estéticos particulares presentes en el arte rupestre hay que prestarle atención a sus rasgos específicos.

\section{APRECIACIÓN ESTÉTICA: INTEGRIDAD, IDENTIDAD, CONDICIONES}

¿Qué es relevante en la apreciación estética del arte rupestre? Siguiendo el modelo esbozado arriba (relacionado con la traducción), quizás sea adecuado empezar con la aplicación de las categorías de nuestro propio contexto cultural que parezcan relevantes. Así, en el caso de las pictografías y de los petroglifos se atendería a la calidad de las líneas, la combinación de colores, la composición, las historias que parecen ser contadas, la relación entre las diversas partes y la totalidad, etcétera. Las características especiales del arte rupestre, sin embargo, pronto nos van a llevar a unas cuestiones fundamentales. Nos podemos preguntar, por ejemplo, si las pictografías y los petroglifos tienen la integridad que normalmente se espera en obras de arte autónomas, ya que a menudo no resulta evidente dónde empieza o acaba una pintura o un grabado particular. Al enfrentarnos a un gran friso rupestre cubierto de representaciones, ¿debería suponerse que cada imagen discernible es una unidad independiente o que todas las imágenes juntas deberían ser vistas como una sola composición? ¿deberían considerarse las superficies rocosas sin representaciones como parte de la unidad a apreciar estéticamente ${ }^{13}$.

Estos parecen ser problemas de difícil solución, pero en realidad se puede aprender de las obras de arte del contexto europeo moderno. Por ejemplo, desde la Edad Media en pintura se han producido trípticos y dípticos. No hay reglas firmes que nos definan si las partes de tales obras deberían ser apreciadas como unidades independientes o como partes de unas totalidades; el espectador se siente libre de ver las obras de una forma y luego de la otra. Igualmente, en la apreciación de un panel de arte rupestre podemos conceder atención a cada representación distinguible por sí sola, a grupos de representaciones, y finalmente al panel en su integridad. En cuanto a la cuestión de si se debiera considerar alguna parte sin representaciones de la pared en que está el panel, se ha de tener en cuenta que hay

13 Estoy en deuda con John Clegg, quien en 1996 me planteó estas cuestiones mientras me mostraba unas obras de arte rupestre exquisitas en la región de Sydney, Australia. Cf. también Halverson (1987) y Bahn (1987:73), en su respuesta a Halverson, sobre la cuestión de si es apropiado suponer que hay 'composiciones' en los paneles de arte rupestre. 
pintores y escultores contemporáneos que a veces han dejado parte de la superficie en que trabajan (sea lienzo, piedra, etc.) sin añadirle representaciones. En estos casos se supone que las superficies que están sin alterar han de apreciarse en relación con las trabajadas. Ciertamente no tenemos razón para suponer que los espacios libres en los paneles de arte rupestre no tengan la misma función.

También podemos preguntarnos si es posible identificar obras de arte individuales, en los casos en que un panel de arte rupestre se ha sometido a adiciones y sustracciones como consecuencia del proceso de superposición de nuevas pinturas y grabados. Parecería que tales cambios ponen en riesgo la identidad de las obras originales presentes ${ }^{14}$. Pero no creo que este temor esté justificado, ya que tales paneles pueden considerarse como un tipo de palimpsestos, o sea, obras de múltiples autores, cada uno de los cuales crea su obra por encima de las contribuciones de su predecesor o sus predecesores (véase también, Davis (1993)). En consecuencia, si es posible establecer que representaciones están superpuestas a otras, se puede desarrollar una valorización de cada capa en relación con las intervenciones precedentes. Lo que parece un solo «lienzo rocoso» puede integrar varias composiciones, cada una de las cuales puede considerarse según sus propias características, en donde uno de los méritos que podemos apreciar es si la integración de nuevas representaciones con las preexistentes fue realizada hábilmente. El palimpsesto que resulta es un tipo de collage de autoría colectiva. Se dan ejemplos de algo parecido en los cascos antiguos de las ciudades históricas donde se van añadiendo edificios poco a poco; a pesar de que varios arquitectos trabajan a través de un tiempo más o menos extendido, tales barrios pueden tener identidades estéticas propias como totalidades, mientras que sus partes también pueden tener valor estético si las consideramos como unidades independientes.

En el caso de los petroglifos y de las pictografías nos podemos plantear diversos interrogantes adicionales respecto a cuáles son los aspectos relevantes en su apreciación estética. Aquí propongo usar una sugerencia proveniente de Paul Ziff quien, en su argumentación de lo que hace un objeto apto para la atención estética, reclama que en cuanto a objetos «tales como las pinturas y las esculturas lo mejor es considerarlas como partituras que esperan su actualización por medio de la interpretación en un momento dado» (Ziff, 1984:134). En general, lo que Ziff argumenta es que, mientras cualquier cosa examinada atentamente puede ser objeto de apreciación estética, todas las cosas tienen sus condiciones de apreciación. Por ejemplo, incluso la apreciación estética de las obras maestras de la pintura puede fallar si falta iluminación o si el espectador no es vidente, mientras que, en contraste, cualquier pieza musical puede ser apreciada igualmente (o aún mejor) sin iluminación, tanto por personas invidentes como videntes.

14 El problema planteado aquí me parece similar al clásico problema de la identidad personal, dados los cambios en la personalidad y la pérdida de recuerdos y adquisición de nuevas memorias a lo largo de la vida. 
Aplicando este principio de Ziff al arte rupestre, nos interesa saber cuáles son las condiciones esenciales para la «actualización» e «interpretación» de sus «partituras", y así poder prestar la atención adecuada a los aspectos relevantes. En un primer plano deberíamos tener en cuenta las condiciones físicas de los grabados y de las pinturas, los cuales en muchos casos sólo se pueden ver a determinadas horas del día, por las condiciones de iluminación necesarias ${ }^{15}$. En un segundo plano deberíamos adentrarnos en las condiciones cognosticivas del arte rupestre. Podemos preguntarnos, por ejemplo, si es relevante tener conocimiento de las ideas que manejaban los creadores de las pictografías y de los petroglifos para su apreciación. O podríamos preguntarnos si se debería tener en cuenta que el material en que está plasmado el arte rupestre es la roca. O también si se debería tener en cuenta la relación entre el panel y su entorno. Las respuestas a estas preguntas están basadas en un enfoque amplio, que tiene en cuenta como estéticamente relevantes un gran número de aspectos perceptibles. La razón por la cual abordo este punto de vista es que supongo que antes de descartar aspectos perceptibles de las obras de arte rupestre debemos tener alguna razón para hacerlo. El principio básico en la apreciación es que, si lo que se ve puede ser el resultado de una decisión de los creadores de esas obras, entonces está a nuestro cargo demostrar que ese aspecto no es estéticamente importante antes de menospreciarlo. Estoy tomando por sentado que, hasta que no tengamos razones que demuestren lo contrario, lo más apropiado es suponer que los autores sí han tenido en cuenta todo lo que pueda interferir, aumentar o modificar el efecto estético de su producción. El resultado de este enfoque en el arte rupestre es ampliar y, con esto, probablemente profundizar nuestra apreciación.

La apreciación de un cierto panel puede ser ampliada, por ejemplo, si se tiene alguna ayuda en su interpretación obtenida por medio de informantes de la sociedad en que se creó la obra, o, si ya no existe esa sociedad, a partir de archivos etnográficos. Tal información puede ser útil en los intentos de llegar a comprender el significado de imágenes complejas. Además, el hecho de que el arte rupestre esté realizado sobre roca es relevante ya que, en parte, parece definir su singularidad por medio de la estabilidad y la durabilidad de la superficie rocosa -la cual de por sí propone su forma, su dureza, su color, su textura, y aún su sonoridad (Waller, 1993) a la apreciación estética-. Es decir, dado que hay otras superficies disponibles, tanto estacionarias (por ejemplo, troncos de árboles, utilizables en dendroglifos; arenales, utilizables en esculturas de arena o en pinturas de arena (como en la tradición de los Navajo)) como movibles (por ejemplo, pedazos de madera, piedras, pieles y telas, o sea todos los otros materiales utilizables en el arte mueble), la presencia de arte rupestre en un lugar concreto tiene un determinado valor estético, tanto por razón del contraste con los otros lugares como por razón del contraste en los materiales utilizados.

15 Juan F. Ruiz López (comunicación personal, agosto 2004) me sugirió mencionar este hecho fundamental para la percepción del arte rupestre. 


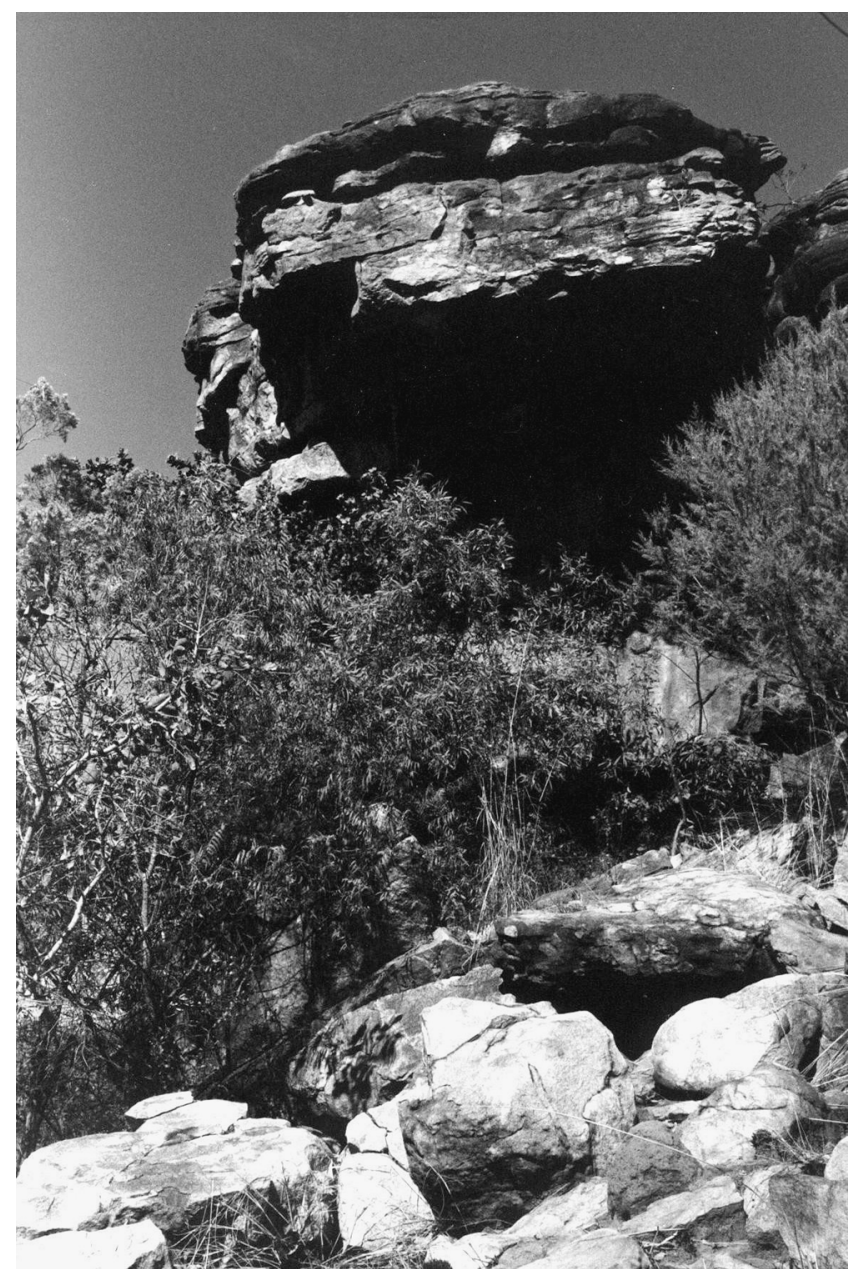

Fig. 3. Abrigo, Kimberleys, Australia septentrional (Thomas Heyd, 2000).

Cada sitio de arte rupestre también constituye una perspectiva particular o ventana a las tierras circundantes. Mi experiencia en la región de Laura es que ciertos paneles sólo eran apreciables desde una posición supina, dentro de una angosta grieta, consciente de las masas rocosas potencialmente fatales en derredor. Otros paneles localizados justo a la orilla del mar, o en acantilados lindantes con ríos o lagos, como, por ejemplo, algunos que se encuentran en la región de Lake of the Woods en Ontario, Canadá, sólo son apreciables adecuadamente desde balsas o botes. Contrastando fuertemente con el arte mueble (que incluye pinturas y esculturas) el arte rupestre tiene localización propia ${ }^{16}$. El arte mueble, tal como se nos

16 De modo notable, la mayoría de las obras de arte contemporáneo llamadas «earthworks» o «land art» dependen de su localización particular. La afinidad en este aspecto entre estas manifesta- 
presenta en museos y galerías de arte contemporáneo, supuestamente es autónomo; se supone que su valor estético es perceptible independientemente del lugar donde sea mostrado. Consecuentemente los museos de arte y las galerías son lugares que buscan neutralizar su entorno de tal manera que las salas del Museo Nacional Centro de Arte Reina Sofía en Madrid no difieren mucho de las salas del Museo de Arte Moderno en México, en cuanto a su efecto sobre la apreciación estética de una pintura de Picasso o de Frida Kahlo. El arte rupestre, en contraste, es enteramente dependiente de, y por tanto está en permanente diálogo con, el lugar en que se halla, ya que no se puede mover sin alterar su carácter de forma fundamental. Por lo tanto, los alrededores de los paneles de arte rupestre resultan ser relevantes para su apreciación estética.

Podemos preguntarnos, sin embargo, si la apreciación estética del arte rupestre, que al fin y al cabo es un arte que está hecho para personas de culturas muy diferentes de las nuestras, no tiene que llevar a un mero «turismo cultural», o sea, a un tipo de experiencia centrada en la estimulación partiendo de la extrañeza de los objetos percibidos. Podemos preguntarnos sobre el significado que puede tener el arte rupestre para nosotros.

\section{SIGNIFICADO DEL ARTE RUPESTRE: ARTE, RESIDENCIAS PASADAS, TIERRA}

Aunque no se puede suponer que los individuos que pertenecen al contexto europeo moderno puedan recuperar exactamente los significados que quisieron transmitir los creadores del arte rupestre ${ }^{17}$, sí se puede constatar que hay muchas personas de nuestras sociedades para quienes la visita a lugares con arte rupestre tiene un significado profundo. Propongo que consideremos el siguiente poema,

ciones artísticas contemporáneas y el arte rupestre ha sido puesto de manifiesto por varios autores. Por ejemplo, Beardsley (1984:8) y Lippard (1983). Quizás se podrían incluir en la categoría de arte que depende de un sitio particular (site-specific) ciertas obras de arquitectura, como el complejo de edificios diseñados por Oscar Niemeyer en Lagoa de Pampulha en Belo Horizonte, Brasil. Muchos diseños de la tradición moderna, sin embargo, precisamente buscaban lograr la autonomía de sus obras respecto al entorno.

17 Denis Dutton (1993) arguye que, al contrario de lo que ocurre con el arte conceptual contemporáneo, la recuperación de los significados de los objetos de arte tradicional no es meramente una cuestión de tener los conceptos apropiados para su interpretación; más bien, «las interpretaciones realmente constitutivas de los artistas tribales normalmente suponen distinciones de percepción» (énfasis añadido; p.20). De lo que concluye que, dado un suficiente conocimiento del contexto cultural de los objetos de arte tradicional, sus significados distintivos pueden ser encontrados en «las cualidades estéticas que intencionalmente han sido incluidas en los objetos para ser vistas» (p. 20) (Cf. también Walton (1970:366-67), quien argumenta que «percibir que una obra [de arte] pertenece a una determinada categoría o grupo de categorías [de arte] es una habilidad que tiene que ser adquirida a través de entrenamiento...»). El problema con la mayor parte de las representaciones de arte rupestre es que, desde luego, generalmente carecemos de suficiente conocimiento de su contexto cultural para extraer de manera fácil los significados que intentaban transmitir. (Véase también el contraste entre arqueología informada y arqueología formal («informed» y «formal» archaeology) propuesto por Christopher Chippindale y Paul S. Taçon en su libro The Archaeology of Rock-Art (Cambridge University Press, 1999)). 
que refleja la experiencia de una visitante canadiense a un sitio con arte rupestre en Laura, Australia.

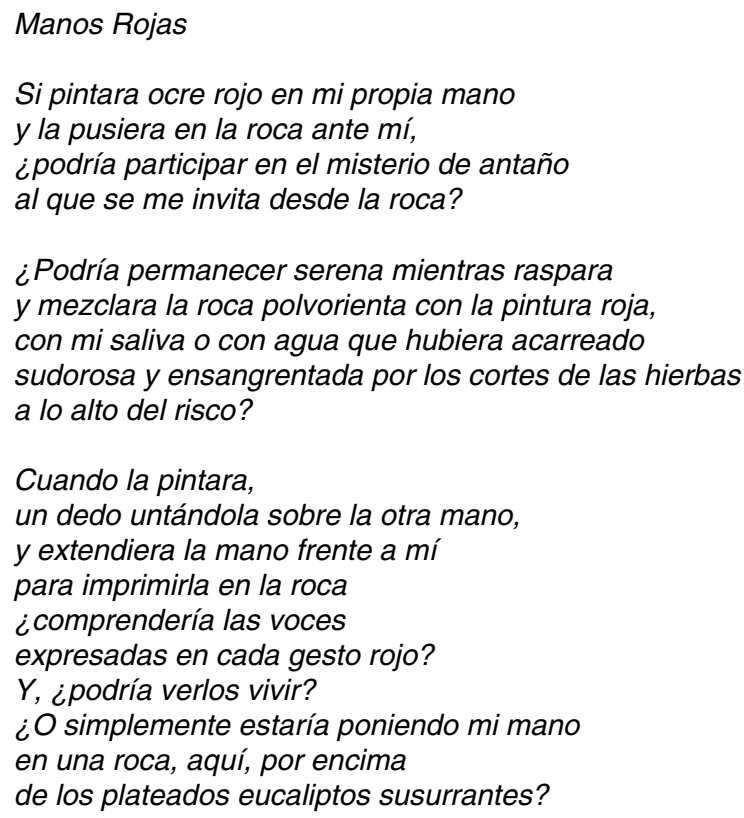

Kari Jones, $1992^{18}$ (traducción de Carmen Rodríguez Cameselle)

${ }^{18}$ El poema original es

\section{Red Hands}

If I painted red ochre on my own hand and placed it on a rock before me, could I partake of the ancient mystery I am beckoned to from the stone?

Could I stand serious while I scraped and mixed dusty smelling rock into red paint with my spit or with water I carried sweaty and bloody from the grass cuts up the ridge?

When I painted it on, one finger smoothing it onto the other hand, and stretched my hand out in front of me to press it on the rock, would I understand the voices expressed by a single red gesture? And could I see them living? Or would I simply be placing my hand on a piece of rock, here, above the silver, whispering gum trees.

Kari Jones compuso este poema en Australia en 1992. 
Este poema combina exquisitamente la atención al trazo como actividad física con su probable importancia como representación de las creencias de los creadores de estos paneles, así como con la atención a su enraizamiento en un lugar particular en el paisaje. Este poema también se muestra sensible al peligro de la intrusión cultural que puede resultar de una interpretación apropiativa; esta sensibilidad está expresada por la manera en que el poema acaba admitiendo que quizás no haya entrada para una forastera a los supuestos misterios representados en las imágenes. Más aún, este poema apunta emblemáticamente la importancia que el arte rupestre puede tener para transmitirnos la idea de que la creación artística es una actividad que tiene sus raíces en los tiempos más remotos de la humanidad. Además nos abre la vista a la percepción del mundo de los que nos precedieron en esas tierras, y por ese camino también nos dirige la mirada hacia las tierras mismas, que siguen constituyendo un trasfondo para toda actividad humana.

«Manos rojas» es un poema inspirado en un sitio de la región de Laura. En esa región a veces se observan imágenes 'positivas' de manos, como las descritas en el poema, aunque son mucho más comunes las improntas o manos 'negativas'. Para crear las imágenes negativas se sopla el pigmento, tal como el ocre rojo, mezclado con un diluyente, tal como el agua, sobre una mano emplazada en la pared rocosa. Cuando el artista quita la mano queda la pintura que 'sobró' alrededor de la mano. Es la 'memoria' de la mano que actuó como modelo. Tales imágenes de manos se pueden encontrar aisladas o en grupos, a veces cubriendo paredes enteras (como, por ejemplo, en la famosa Cueva de las Manos, en Patagonia). Tienden a ser imágenes estéticamente atractivas y bellas a pesar de su simplicidad.

La existencia de imágenes simples, como la representación de manos, junto a otras más elaboradas, de seres humanos y de los animales característicos de Australia, los emús, los canguros, las zorras voladoras, demuestra que, al menos ocasionalmente, el arte rupestre ha sido creado por personas que precisaban de relativamente poco adiestramiento. A juzgar por el tamaño de algunas de las representaciones de manos es evidente que hasta los niños participaron a veces en su creación. Si también se tiene en cuenta que se pueden encontrar representaciones de animales altamente logradas, pintadas incluso con un cierto sentido de la perspectiva, que datan de 32000 años atrás (como en la Grotte Chauvet) hay que repensar la tan añorada idea del «progreso» en el arte; en vez de una progresión unidireccional de lo simple a lo complejo, la condición humana parece ser tal que la creación artística llegó a grandes logros en épocas muy anteriores a lo que jamás se habría creído posible ${ }^{19}$. Es decir, el arte rupestre nos provee de evi-

19 En este contexto el descubrimiento de una flauta de hueso, datada a entre hace 43000 y 82000 años, que se asocia con los Neandertales, es significativo. La flauta aparentemente estaba afinada en la escala do-re-mi (diatónica) (Fink, 1997), lo cual significa que algunos Neandertales podrían haber sido capaces de producir música semejante a la nuestra en ciertos aspectos importantes. Este descu- 
dencia empírica de primera mano de una continuidad fundamental en la capacidad humana de exhibir actitudes y disposiciones artísticas a través del tiempo y del espacio.

Además de los marcadores naturales en el paisaje, los sitios con arte rupestre constituyen una suerte de paneles informativos para el viajero itinerante ${ }^{20}$. Pero, contrastando con los marcadores naturales, los lugares con arte rupestre constituyen claros recordatorios del hecho de que ciertas tierras están «repletas de significados" (Bradley et al., 1994; Taçon, 1994; Ouzman, 1995). Esto se hace muy evidente para los que vienen de la ciudad y que llegan a lugares como las zonas agrestes de Australia o de América del Sur. Mientras en un principio el terreno parece monótono, con facciones todas iguales en sus inmensas distancias, sus distintas partes rápidamente se hacen evidentes en sus particularidades una vez que se llega a conocer los lugares marcados de alguna forma, por ejemplo, con arte rupestre.

El hecho de que hubo seres humanos que se detuvieron en esos parajes durante el tiempo suficiente para crear arte rupestre transforma la tierra, haciéndola al mismo tiempo extraña y también ya conocida ('ya vista' por otros seres humanos), $y$, por tanto, puede servir de punto de enfoque para nuestra curiosidad (véase también Schaafsma, 1988). Para comprender de qué se trata podemos comparar el efecto del arte rupestre con el efecto del arte paisajista contemporáneo de un artista rumano, Christo. Tiene fama por haber cubierto multitud de edificaciones con plástico, pero también zonas costeras e islas. Sin transformar la tierra en objeto artificial, como ocurre por medio de la agricultura y la minería, el arte rupestre, como el arte de Christo, transforma la tierra en paisaje, esto es, en «un terreno en que los rasgos culturales han reemplazado [por lo menos parcialmente] esos elementos naturales que sirven de referencia geográfica a los pueblos nómadas» (Bradley, 1991:77).

La transformación de la tierra en paisaje efectuada por medio del arte rupestre nos recuerda que estas manifestaciones son una marca del espíritu. Aunque radicalmente incompletas (ya que nos falta la mayor parte del contexto cultural de sus creadores), si se consideran como «partituras que esperan su actualización por medio de la interpretación", estas representaciones en la roca revelan los gestos de sus creadores, al menos parcialmente. Se nos ofrecen las huellas del espíritu de los que rondaron la tierra antaño y se detuvieron en la zona lo bastante para hacer pinturas y grabados rupestres, por lo que la apreciación estética del arte rupestre puede llevarnos a una mejor comprensión de las mujeres y de los hombres que dejaron esas representaciones.

brimiento también podría servir para apoyar el argumento que la creación de obras artísticas se remonta a gran profundidad en el tiempo (Fink sugiere que «si los Neandertales hicieron realmente la flauta, significa que eran más humanos e inteligentes de lo que pensábamos»).

20 Cf. también Hartley (1992:10-14), «Compiling Knowledge about the Environment». 
Después de la transformación de la tierra en paisaje por medio del arte rupestre la tierra ya no puede ser percibida ni como enteramente ajena ni como mero recurso económico. El arte rupestre nos sugiere que la tierra ha sido vista como hogar, y por lo tanto, devuelve nuestra mirada al paisaje, invitándonos a su apreciación estética (Heyd, 1999b). En cuanto que el arte rupestre, estando situado en la roca, es parte de la tierra, su presencia la hace reverberar: la belleza de los trazos sobre las rocas nos recuerda la belleza de la misma tierra ${ }^{21}$.

\section{AGRADECIMIENTOS}

Le doy las gracias especialmente a John Clegg, quien primero me enseñó cómo mirar el arte rupestre con la atención debida, y luego mejoró el artículo original en su versión inglesa con muchas sugerencias fundadas en su gran experiencia y su profundo conocimiento del arte rupestre. También les estoy agradecido a Brian Butterworth, Alice Buhrich, Kari Jones, Michael Pardy y a Laurie Abel por las estimulantes conversaciones sobre estos temas. Además les doy las gracias a Isabel Leal y a Moraia Grau por su valiosa ayuda en la traducción de este ensayo. Finalmente estoy en deuda con Juan Francisco Ruiz y Martí Mas, así como con Elena y Carmen Rodríguez Cameselle, quienes revisaron el artículo y me hicieron múltiples, excelentes sugerencias para su mejora en gramática y sintaxis. A Carmen Rodríguez Cameselle le debo además la muy acertada traducción del poema Red Hands.

\section{BIBLIOGRAFÍA}

BAHN, Paul G. (1987): Commentario de Halverson, John (1987): «Art for Art's Sake in the Paleolithic», Current Anthropology, 28, pp. 63-89.

BarRY, P. S. (1991): Mystical Themes in Milk River Rock Art, University of Alberta Press, Edmonton.

BeARDSLeY, John (1984): Earthworks and Beyond: Contemporary Art in the Landscape, Cross River/Abbeville Press, New York.

Blocker, H. Gene (1994): The Aesthetics of Primitive Art, University Press of America, Lanham.

BRADLEY, Richard (1991): «Rock Art and the Perception of Landscape», Cambridge Archaeological Journal, 1, pp. 77-101.

-, Criado Boado, Felipe y Fábregas Valcarce, Ramón (1994): «Rock Art Research as Landscape Archaeology, " World Archaeology, 25, pp. 374-90.

CLIFFORD, James (1988): «Histories of the Tribal and the Modern,» en The Predicament of Culture: Twentieth-Century Ethnography, Literature and Art, Harvard University Press, pp. 189-214.

Cole, N. A (1995): «Rock Art in the Laura-Cooktown Region, S.E. Cape York Peninsula», en Morwood, M. J. y Hobbs, D.R. (eds.): Quinkan Prehistory: The Archaeology of Aboriginal Art in S.E. Cape York Peninsula Australia, Tempus, 3, pp. 51-69.

- y PERCY, Trezise (1992): «Laura Engravings - a Preliminary Report on the Amphitheatre Site», en McDonald, Jo y Hascovec, Ivan P. (eds.): State of the Art: Regional Rock Art Studies in Australia and Melanesia, Australian Rock Art Research Association, Melbourne, pp. 83-88.

21 Una primera versión de este ensayo, ahora corregida y ampliada, apareció en inglés (Heyd, 1999a). Véase también Heyd y Clegg (2005) y Heyd y Clegg (eds.) (en prensa). 
DANTO, Arthur (1977-89): «The Artistic Enfranchisement of Real Objects: The Artworld», en Dickie, George, Sclafani, Richard y Roblin, Ronald (eds.): Aesthetics: A Critical Anthology, St. Martin's Press, New York, pp. 196-205.

DavIS, Whitney (1993): «Beginning the History of Art,» Journal of Aesthetics and Art Criticism, 51, pp. 32750.

DICKIE, George (1977-89): «The New Institutional Theory of Art», en Dickie, George, Sclafani, Richard y Roblin, Ronald (eds.): Aesthetics: A Critical Anthology, St. Martin's Press, New York, pp. 171-82.

DutTon, Denis (1993): «Tribal Art and Artifact», Journal of Aesthetics and Art Criticism, 51 (1), pp. 13-22.

FINK, Bob (1997): «How I Proved Ancient Bone is Do-Re-Mi Flute», Globe and Mail, pp. D5.

Gombrich, E. H. (1984), The Story of Art, Phaidon, Oxford.

Halverson, John (1987): «Art for Art's Sake in the Paleolithic,» Current Anthropology, 28, p. 63-89.

HARTLEY, Ralph J. (1992): Rock Art on the Northern Colorado Plateau: Variability in Content and Context, Avebury, Brookfield, Vermont.

HEARTNEY, Eleanor (1994): «Recontextualizing African Altars», Art in America, 82 (12), pp. 58-65.

HeYD, Thomas (1999a): «Rock Art Aesthetics: Trace on Rock, Mark of Spirit, Window on Land», The Journal of Aesthetics and Art Criticism, 57 (4), pp. 451-458.

- (1999b): «Rock Art and the Aesthetic Appreciation of Natural Landscapes», en News95. International Rock Art Congress, Centro Studi e Museo d'Arte Preistorica, Pinerolo. Publicado también en (2007a), Encountering Nature: Toward an Environmental Culture, Ashgate, Aldershot, Inglaterra.

- (2007a): Encountering Nature: Toward an Environmental Culture, Ashgate, Aldershot, Inglaterra.

- (2007b): "Cross-cultural contact, etiquette and rock art», Rock Art Research, 24, pp. 191-98.

— y CLEGG, John (eds.) (2005): Aesthetics and Rock Art, Ashgate, Aldershot, Inglaterra.

- (eds.) (en prensa): Aesthetics and Rock Art. III Symposium, en Luiz Oosterbeek (ed.): Proceedings of the XVth Congress of the UISPP, Union internationale des sciences préhistoriques et protohistoriquesBAR.

JONES, Kari (1999): «Red Hands», en Journal of Aesthetics and Art Criticism, 57, pp. 451-458.

KeYSER, James D. (1992): Indian Rock Art of the Columbia Plateau, University of Washington Press, Seattle \& London.

LeVInSon, Jerrold (1996): «Extending Art Historically», en The Pleasures of Aesthetics: Philosophical Essays, Cornell University Press, Ithaca \& London.

LIPPARD, Lucy R. (1983): Overlay: Contemporary Art and the Art of Prehistory, Pantheon.

MeIGHAN, Clement W. (1996): «Human Nature and Rock Art Production», Rock Art Research, 13, pp. 6870.

MoRwood, M.J. (1992): «Changing Art in a Changing Landscape: A Case Study from the Upper Flinders Region of the North Queensland Highland", en McDonald, Jo y Haskovec, Ivan P. (eds.): State of the Art: Regional Rock Art Studies in Australia and Melanesia, Australian Rock Art Research Association, Melbourne, pp. 60-70.

MulvaneY, Ken (1996): «What to Do on a Rainy Day: Reminiscences of Mirriuwung and Gadjerong Artists», Rock Art Research, 13, pp. 3-20.

OTTEN, Charlotte M. (ed.): Anthropology and Art: Readings in Crosscultural Aesthetics, Natural History Press, New York, pp. 247-281.

OuZMAN, Sven (1995): «Spiritual and Political Uses of a Rock Art Engraving Site and Its Imagery by San and Tswana-Speakers", South African Archaeological Bulletin, 50, pp. 55-67.

SchaAfsma, Polly (1988): «Rock Art: Ideas in Time and Space», en Linda Connor, Rick Dingus, Steve Fitch, John Pfahl y Charles Roitz (eds.), en Marks in Place: Contemporary Responses to Rock Art, University of New Mexico Press, Albuquerque, pp. 1-5.

SHINER, Larry (1994): “'Primitive Fakes', 'Tourist Art' and the Ideology of Authenticity», Journal of Aesthetics and Art Criticism, 52.

TAÇON, Paul, S.C. (1994): «Socialising Landscapes: The Long-Term Implications of Signs, Symbols and Marks on the Land", Archaeological Oceania, 29, pp. 117-129.

UCKo, Peter J. y Rosenfeld Andrée (1971): «Critical Analysis of Interpretations, and Conclusions and Problems from Palaeolithic Cave Art?, en Otten, Charlotte M. (ed.): Anthropology and Art: Readings in Crosscultural Aesthetics, Natural History Press, New York, pp. 247-281.

WaLton, Kendall L. (1970): "Categories of Art», Philosophical Review, 49.

WALLER, Steven J. (1993): «Sound Reflection as an Explanation for the Content and Context of Rock Art,» Rock Art Research, 10, pp. 91-101.

ZIFF, Paul (1984): Antiaesthetics: An Appreciation of the Cow with the Subtile Nose, D. Reidel, Dordrecht. 